\title{
EFL Students' Perceptions of Using Portfolio Assessments in the Writing Classroom: The Case of Libyan Undergraduate Second Year Students
}

\author{
Hameda Suwaed \\ Department of English, College of Arts, University of Sabratha
}

Received: May 17, 2018 Accepted: May 29, 2018 Published: May 29, 2018

doi:10.5296/jse.v8i2.13152 URL: https://doi.org/10.5296/jse.v8i2.13152

\begin{abstract}
The aim of this study was to investigate EFL second-year students' perceptions towards using portfolio assessments in their writing courses. It was also intended to discover the exam preference of the participants. The participants of the study were 38 Libyan EFL students enrolled in second-year courses in the Department of English. Data were collected by using a questionnaire, student portfolios and semi-structured interviews with eight participants. The results indicated that the participants generally preferred to be evaluated by portfolio assessments. Most of them believed that portfolio assessments improved their writing and enhanced their motivation. However, some participants preferred traditional pen-and-paper tests.
\end{abstract}

Keywords: portfolio, EFL context, students' motivation, autonomy 


\section{Introduction}

Nowadays, English language teaching methods are shifting from the traditional way of transition of knowledge to the information and skills students will need to succeed in the real world. The current approaches focus on teaching students critical thinking, communication and problem solving. Teaching writing skills is not an exception. There has been a shift in teaching writing, from focusing on an accurate product to the process of writing itself. Consequently, the process of brainstorming, drafting, writing and editing cannot be tested in traditional timed tests (Alhosni, 2017; Caner, 2010).

Teaching and assessing English writing skills are more challenging in the English as a foreign language (EFL) context. According to Johns (1991), it is more difficult to assess EFL students' writing abilities than those of native speakers in timed writing tests. Similarly, Song and August (2002) added that, in timed tests, EFL students cannot focus on the skills needed for English writing.

Therefore, new types of assessments have been used to assess student learning and ways that writing can be used in context (Caner, 2010). Portfolios are one of the alternatives that can be used to assess writing skills. A portfolio is a collection of writing products that indicates the students' writing ability and learning progress. According to Hedge (2000), portfolios are a better indicator of students' writing ability than timed tests. Fithri (2015) mentioned that portfolios offer many possibilities for teachers and students to actively participate, get involved in learning activities and continuously monitor the students' learning progress. The students' collection of documents can be varied, such as essays, reports and other types of writing. Portfolios provide evidence of students' progress, which enables the teachers to review all the students' work throughout the academic year.

Although portfolios have many benefits for students, they are not widely used in the Libyan EFL context, where students are usually given marks for their end-of-term writing tests. This kind of assessment might not reflect students' writing ability, as these tests measure the accuracy of the answers rather than the process of writing a composition. The limited implementation of portfolios in the Libya EFL context can be attributed to the following reasons: the writing teachers may find portfolios time-consuming, as checking portfolios regularly requires more time than preparing pen-and-paper exams; the teachers may not be aware of the benefits of using portfolios, such as improving students' writing ability; and the teachers may be unaware of alternative assessment tools, such as portfolios.

Whilst various studies have been conducted to measure the impact of portfolios on students' writing and the potential benefits to learning, there has been little research that has investigated EFL undergraduate students' perceptions about the use of portfolios in writing assessments in the Libyan context. Therefore, this study aimed to investigate students' views of using portfolios to encourage writing teachers to use portfolios for writing assessments, as well as to help the teachers attain an in-depth understanding of the benefits of using portfolios from the perspective of EFL undergraduate students. 


\section{MInstitute"}

\section{Literature review}

\subsection{Definition of a Portfolio}

A portfolio is defined as "a systematic collection of "students work that is analysed to show progress over the period of time with regard to specific instructional goals" (Winch et al., 2001, p. 272). Furthermore, a portfolio is also defined as "the collection of evidence that demonstrate skills, achievements, learning, and competencies" (Cooper, 1999, p. 3). As an alternative language assessment tool, portfolios are very flexible to implement in the classroom and can be designed for a variety of purposes. Moreover, portfolios can be adapted according to students' needs (Fithri, 2015). In addition, portfolios provide opportunity for students to be engaged in a meaningful learning process, as they may be allowed to decide for themselves the type of writing and the topics about which they are going to write. Caner (2010) pointed out that portfolios have become an alternative to traditional tests because they provide more validity by integrating instruction and evaluation. In addition, portfolio assessments might enhance student-centred learning.

Hamp-Lyons and Condon (2000) stated nine characteristics of portfolios:

- A portfolio is a collection of written assignments rather than a single work.

- It gives the learners a chance to write in different genres for different purposes and readers.

- A portfolio demonstrates what learners have achieved.

- It gives students the opportunity to edit and revise their writing before the final evaluation.

- It gives students the opportunity to select the written product to be included in the portfolio.

- It gives students a sense of control when selecting and revising their writing before putting it in the portfolio.

- An important characteristic of portfolios is reflection and self-assessment, in that students reflect on their improvement as writers.

- It measures students' improvement, such as linguistic accuracy or how to improve an argument.

- Portfolios reflect progress over time.

Of these nine characteristics, Weigle (2002, p. 200) argued that the most important components are collection, reflection and selection. Since the aim of portfolios is to provide evidence of students' progress, a collection of written samples might indicate the students' level more than a single assignment. Consequently, the selection of the written products and the reflection about the order and form of the writings and why they were chosen are essential to 'turn[ing] a collection of writing samples into portfolios'. 


\subsection{Portfolios Assessment in EFL Classrooms}

There are numerous benefits of keeping a portfolio as an alternative assessment tool. In language assessments, some research findings have proved that portfolios have increased students' achievement and their motivation to learn the language (Zhang, 2009). For learners, Phye (1997) stated that portfolios encourage self-assessment, which leads learners to practise independent learning; portfolios also provide more chances to develop learners' skills. They can learn and improve their writing skills through their teachers' comments on their portfolios and share their work with other students.

Similarly, Paesani (2006) indicated that portfolios help to improve students' grammatical competence and language proficiency. In a similar study, Ozturk and Cecean (2007) investigated the influence of portfolios on EFL learners' writing anxiety. The findings show that portfolios are beneficial to reducing learners' anxiety and enhancing their motivation to write. According to Huang (2012), portfolios enable students to improve their ability to communicate, as they write in class and out of class. In addition, keeping portfolios gives students an opportunity to elicit feedback not just from the teacher, but from their peers, as well.

The findings in Burksaitiene and Tereseviciene's (2008) study, which aimed to investigate students' perceptions of using portfolios in learning English for law, indicated that using portfolios is beneficial in motivating students to learn a foreign language. In addition, it enhances student satisfaction and encourages them to take control of their learning. Fostering learner autonomy is one of the main features of portfolio assessments. According to Banfi (2003), "the flexibility of portfolios is considered to make them ideal tools for encouraging learner autonomy" (p. 34). According to Alhosni (2017), portfolios have benefits for both teachers and learners, as portfolios provide evidence about language learners' learning progress. At the same time, teachers can check and reflect on the effectives of their teaching practices (Paris \& Ayres, 1994).

Although there are numerous advantages of using a portfolio approach in EFL classrooms, implementing this alternative tool has entailed many challenges for language teachers and learners. According to Phye (1997), teachers might be demotivated to use portfolio assessments due to the time needed for evaluation, as it is a time-consuming process for both learners and teachers. The findings from Pollari's (2000) case study showed that the majority of the students liked portfolio assessments, stating that keeping a portfolio helped them to be more autonomous. However, some of the participants expressed their refusal of the approach, as they considered it unsuitable for them.

However, studies that investigate EFL undergraduate students' perceptions on using portfolios assessment in EFL writing appear to be limited. Thus, this study aims to investigate EFL undergraduate Libyan students' perceptions about the benefits of keeping portfolios, the challenges that they face and their exam preferences. Therefore, the current study may be beneficial by filling a gap in the literature on portfolio assessment in the EFL context in relation to undergraduate students' perceptions. 


\section{Methodology}

\subsection{Research context}

The current study took place at the Department of English in the Faculty of Arts at Sabratha University. The department was established in 2000. It offers a variety of courses, including literature, language skills, applied linguistics and translation. All staff members in the department are Libyan. Some of them graduated from the Libyan Academy, whereas others received their degrees from native English-speaking countries.

\subsection{Participants}

The participants of this study were thirty-eight second-year students studying in the English department in the Faculty of Arts at Sabratha University. Thirty-four of the participants were females and four were males. All of them have studied the English language for eleven years. Their ages range from 18-20 years old.

\subsection{Research design}

Both qualitative and quantitative tools for data collection and analysis were adopted in this study to ensure methodological triangulation (Cohen et al., 2007). Data were gathered from a questionnaire, semi-structured interviews and students' portfolios.

\subsection{1 questionnaire}

The questionnaire was used by the researcher to investigate the second-year students' perceptions of portfolios as alternative assessment tools. An open-ended questionnaire was chosen because it would give more detailed data concerning the students' comments about portfolios as an alternative assessment. In addition, this questionnaire was designed to collect qualitative data in order to investigate the students' knowledge and understanding about portfolio assessments.

The questionnaire consisted of two sections: a demographic information section with five questions about the students' age, gender, how long they had been learning the English language and their opinion about their level of English proficiency; section two had 10 open-ended questions about their knowledge related to the purpose of portfolios, the benefits of using portfolios, the difficulties they faced in keeping portfolios and their exam preference.

The questionnaire was adapted from Chung's (2012) questionnaire, whose validity and reliability has been checked and verified. In addition, the questionnaire was revised by two faculty members from Sabratha University to ensure its validity. It was modified in light of their feedback before distributing it.

\subsubsection{Semi structured interview}

The data from the questionnaire was supported by semi-structured interviews with eight students and samples from students' portfolios. A total of 12 students volunteered to be interviewed, of which eight showed up for the interview. The interview questions were 
mainly about the students' views about the use of portfolios as assessment tools in writing classrooms and the students' preferences of exam type. The interview lasted about 25 minutes. It was in English with occasional use of the Arabic language.

\subsection{Process of Data collection and Analysis}

Upon obtaining permission from the head of the department and the second-year writing teacher, the researcher met all second-year students to inform them about the aim of the research, from which 38 students agreed to participate. It was highlighted that filling out the questionnaire and participating in the interviews were purely voluntary, and that the answers would be confidential. Then, the questionnaire was distributed to the students in person. The total administration time was estimated to be approximately 45 minutes.

With regard to the data analysis, students' responses to the open-ended questions were categorised as benefits and challenges towards the use of portfolios in the writing classroom, and then the frequency of the responses was calculated. Qualitative data were categorised by using the content analysis method, and the findings of the study were divided into three main themes: the benefits of portfolios for second-year writing skills, the disadvantages of keeping portfolios and the second-year students' exam preferences.

\subsection{Research questions}

This study aims to answer the following research questions:

1. What do EFL second-year students think about the use of portfolios in their EFL writing class?

2. Which assessment tool - portfolios or pen-and-paper tests - do EFL students prefer in their writing classes?

\section{Findings and discussion}

\section{What do EFL second year students think about the use of portfolios in their EFL writing class?}

Students were asked about dis/advantages of portfolio assessments on the questionnaire. Most of the participants in this study mentioned that portfolios are advantageous to them. The benefits are presented and discussed as follows:

1) Improving writing skills

All the participants mentioned that keeping portfolios helped them to improve their writing ability and its sub-skills. However, there was no agreement amongst the participants about which skills they had improved the most, which can be attributed to their mixed ability in learning the English language. Eight of the participants asserted that keeping a portfolio in writing helped them to improve their grammatical competence, which helps them to write more accurate sentences and paragraphs. Moreover, it helps them to write various sentence types, such as complex and compound sentences. S3 stated: 'I keep looking at my mistakes 
and try to avoid them. This helped me to write with fewer grammatical mistakes, such as the appropriate tenses'.

In addition, twenty-five students mentioned that portfolios helped them to organise their ideas in writing paragraphs. In other words, they learned the stages of writing: pre-writing activities, such as brainstorming, writing the first draft and, finally, editing their paragraphs according to the feedback they receive from their teacher or peers. This is in line with the students' answers in the interview, as they mentioned that keeping portfolios helped them write coherent paragraphs. S1: 'I can write more in English without thinking in Arabic and then translating it. Also, I know the structure of the paragraph and how to link my ideas together to write original paragraphs'. S6 added: 'I've learnt how to use linking words, and this improved my ability to write coherent paragraphs'. This is corresponding with Aydin's (2010) research findings, which showed that portfolios make students more aware of the characteristics of paragraphs and the use of language in context without relying on translation.

Furthermore, thirteen students mentioned an improvement in micro-skills, such as punctuation and capitalisation. S5: 'In my first paragraphs, I had many mistakes regarding punctuation and spacing. But, over time, the mistakes are fewer'. S4 mentioned: 'The portfolio helped me to improve my writing in terms of using punctuation marks. I used to write without paying attention to them or to capitalisation'.

These results support earlier findings in the literature. It is consistent with the findings from Ghoorchdi et al. (2010), which demonstrated that portfolios influence the students' level in writing in terms of organisation and vocabulary. Furthermore, these results correspond with Yurdabakan and Erdogan's (2009) findings, which indicated that keeping portfolios improves students' overall writing ability.

2) Having a sense of achievement

All students mentioned that a major advantage of portfolio assessments was being able to notice improvement over time. S7 said: 'When I look at my assignments and compare them, I feel happy because I can notice the progress'. Similarly, S23 said: 'Keeping a portfolio is good for me because it is evidence of my improvement over time. For example, over time, my writing started to be more academic'.

In addition, twelve students mentioned that their portfolios could be a good resource for other writing assignments in the future. Consequently, this enhances their motivation and engagement in the writing classroom. S6:'Portfolios are really a good learning experience for us as EFL students. It motivates us to learn the English language and to see our progress'.

According to Alhosni (2017), portfolios reflect the amount of effort that students exert in their preparation and writing, as well as students' progress in their learning. Portfolios demonstrate students' progress, ideas and learning processes. It also fosters a collaborative learning environment in which students feel motivated to share their ideas and receive feedback from their peers (Huang, 2012). 
This is consistent with the students' answers in the interview, in which S4 mentioned: 'What is good about portfolios is that you keep your writings and can view your progress over time'. In a follow-up question about students' reflections on their writing, the interviewed students mentioned that the writing teacher asks them to compare their answers and discuss common mistakes. According to Caner (2010), one of the important benefits of keeping a portfolio is that it makes students realise how well they have learned topics, what they have not learned yet and what they still need to improve.

3) fostering learning autonomy

Twenty students mentioned that keeping portfolios helps them to be more autonomous. They can work on their own in preparing, writing, editing and assessing their work. S1 said: 'I feel more confident in writing class and in my evaluation. Similarly, S4 mentioned: 'I am more independent in writing class than other subjects, because I can prepare information about the given topic, write more than one draft and assess my writing'. According to Huang (2012), having this experience enables students to be aware of their strengths and weaknesses, set goals and check their learning progress.

This is in line with Fithri's (2015) research findings, which showed that learners believe that a portfolio is motivating and appealing because it enables them to be autonomous. In addition, Hung (2009) mentioned that "portfolios provide an opportunity for learners to monitor their own progress and take responsibility for meeting goals" (p. 131).

Through the interview answers, five students mentioned that keeping portfolios helped them to learn new habits such as taking responsibility of keeping a portfolio folder and submission deadlines. In addition, keeping portfolios enhanced their motivation and enabled them to move from being passive learners to playing a more active role. S7: 'I've learned to be more responsible by keeping my assignments in a file'. S4 added: 'I feel more motivated than before about the writing class'. Consequently, this leads the students to be more autonomous learners. Caner (2010) asserted that portfolios can be used to encourage students to take control of their learning rather than being passive receivers of information.

The findings of the current study highlighted the fact that portfolio assessments, as a teaching and assessment device, give students a sense of control over their learning and enhance their motivation. This indicates that the portfolios require changes in the teachers' roles, from controller towards teacher as a facilitator (Nezakatgoo, 2011).

Although all the students who participated in this study had positive attitudes towards portfolios, a few students mentioned the following disadvantages of using portfolio assessments in the writing classroom.

1)Excessive time and effort needed

The first problem, which was mentioned by six students in the questionnaire, was that portfolios are time-consuming. They indicated that the portfolios require a lot of time to write, rewrite and edit. They felt overloaded from assignments and believed that portfolios are an extra burden for them, because they had other assignments and preparations for other subjects 
and could not devote themselves fully to only writing. S10 wrote: 'I dislike this approach because it needs a lot of time, and I sometimes cannot find time because I am busy with other homework and preparation for other teachers'.

As identified in the literature, the portfolio process is time-consuming and needs consistent encouragement. This was in accordance with the students' answers in the interview, as I asked the students about the challenges they face in keeping portfolios. Three of them stated that portfolio would be effective for learning if they had extra time for the tasks. S2 said: 'Portfolios would be advantageous if we had more time for writing and more ideas'. These negative views about portfolios might show that students are overloaded in their learning with preparation and assignments. This is consistent with the findings from Huang (2012), which indicated that students consider portfolios to be tiring and require a long time to complete. Similarly, Aydin's (2010) findings indicated that keeping portfolios is a time-consuming and boring process.

\section{2) Lack of vocabulary and content knowledge}

Five students mentioned that portfolios and writing about different topics require a vivid vocabulary and ideas that they lack. S9: 'My main problem is vocabulary. I do not have that much vocabulary, so I keep repeating myself. S30 wrote: 'Portfolios are good for the smart students, not the weak ones. I find it hard to write about different topics and express my ideas'.

According to Alhosni (2017), the language barrier is one of the main challenges that can cause portfolios to be a burden for EFL learners. Facing the challenge of a lack of vocabulary might hinder student engagement in this new experience. Instead, they feel less confident about their ability to write. Here, it is important to create direct prompts to enhance students' self-confidence, as most students consider writing to be a difficult subject. In addition, writing teachers can support their students by giving them constructive feedback (Fithri, 2015). Arranging small groups and asking learners to evaluate one another's portfolios or discuss and share ideas might help the students learn how to select, reflect and write.

\section{Which assessment tool - portfolios or pen-and-paper tests - do EFL second-year students prefer in their writing classes?}

With regard to exam preference, the results show that the majority of students (35 students) mentioned that they prefer portfolio assessments rather than pen-and-paper tests. Furthermore, they consider portfolios to be more advantageous and effective. S5: 'It is natural and encouraging, compared with traditional timed exams'. Similarly, S14 said: 'I highly recommend portfolios to be used even in other subjects, not just writing'. This is in line with Huang (2012), who pointed out that most students have positive attitudes towards portfolio assessments compared with traditional tests. Portfolios have proven their superiority compared with traditional pen-and-paper tests because they help students show what they can do, as opposed to what they can produce in traditional timed tests (Tannenbaum, 1997). 
The students' responses showed that most students are aware of the advantages of the implementation of portfolios in the writing classroom; therefore, they prefer to be evaluated by portfolios. This is in contrast with Caner (2010), who stated that most of the participants in his research did not prefer to be evaluated by portfolios and preferred traditional assessments instead.

In general, the participants of this study preferred portfolio assessments to traditional assessments because they believed that traditional assessments involved time pressure and did not measure their writing ability effectively. However, three students mentioned that they are not comfortable with portfolios as an assessment method because they are used to traditional ones i.e. pen-and-paper tests. S15 said: 'It is scary sometimes, because I am not used to it. To have questions and answer them in an exam is easier and clearer than the portfolio'.

It is worth mentioning here that tests play a crucial role in the Libyan educational system. Undergraduate students have to pass numerous exams in order to get their degree. Each term, they have to take at least two tests in each subject: a mid-term exam and a final exam. In addition, grades are placed at the top of Libyan students' priorities, since they are the only type of assessment used in most educational institutions.

These results correspond to the students' answers in the interview, as most students showed positive attitudes towards using portfolios. However, some showed a lack of motivation and confidence about their skills in having portfolios as an assessment tool. This is not surprising, as portfolios are not familiar to the students, and they are heavily influenced by traditional tests. It takes time for to become accustomed to alternative assessments and acquire the needed skills and knowledge.

It is obvious that some students, mainly those who mentioned that they lack the needed vocabulary and structure, are still afraid to practise authentic learning. For them, it is a risk, and they might lose marks. They are used to being passive learners in teacher-centred classes, not being autonomous, taking responsibility for trying new approaches and reflecting on them (Alhosni, 2017).

Traditionally, the Libyan educational system is confined to standardised tests to measure students' knowledge. It is widely believed that the quality of teaching is demonstrated by students' test scores. Thus, according to Klenowski (2002), "When the portfolios are implemented, the prevailing understanding of the nature and purpose of assessment sometimes militates against their success... attitudes of students and teachers are difficult to change in institutions and contexts where traditional conceptions of assessment use, such as for measuring learning, dominate" (p. 79). In addition, when new evaluation tools are used in an old paradigm, it is likely that it will have a limited effect (Mabry, 1999).

\section{Conclusion and Recommendations}

Several findings can be summarised from the current study. First, students significantly favour portfolio assessments. They considered the use of portfolios beneficial for them to improve their writing skills. The advantages of portfolios that were categorised in the 
students' responses in the questionnaires included improving their writing skills, gaining a sense of achievement and enhancing their self-confidence and motivation.

The disadvantages identified were that the portfolios are time-consuming and that the learners may lack the vocabulary and skills needed to execute the writings properly.

Consequently, the interview findings also confirmed that students benefited from portfolios. It was mentioned that the students' self confidence in using the English language increased, and that they had a sense of progress when they compared their writing assignments over time.

However, some students might not perceive the immediate effect of portfolios, compared to traditional tests. The second-year students' negative views about the use of portfolios are not surprising, because they are still influenced by the traditional tests and only know a little about alternative assessment tools. It takes time and effort from their writing teachers to train them about using alternative tools and support them with the guidance and checklists needed.

Based on the findings of the current study, I recommend the following:

In service training, programs should be provided for EFL writing teachers to enhance their teaching and evaluation skills.

Students' positive views towards portfolios and the results of the analyses show that writing teachers should consider integrating portfolio use into their assessments as a supplementary assessment tool to improve students' writing and foster autonomy.

However, writing teachers should take into consideration that a careful, systematic, well-organised preparation is essential. Before the implementation, portfolio keeping should be introduced to the students to guide them, especially if portfolios will be used as an assessment tool for the first time.

It is important for the teachers to provide a supportive environment where students can share their thoughts and writing to become more autonomous.

\section{Suggestions for further research}

Further research can be realised at different levels and with more participants to measure the effect of portfolios on students' writing ability. In addition, a longitudinal study can be conducted to explore the influence of portfolios on students' proficiency over time. Furthermore, EFL writing teachers' perceptions about the use of portfolios and the challenges of implementing them in context can be an important area of investigation.

\section{References}

Alhosni, J. (2017). New Perspective on Portfolios in EFL Classrooms: Portfolio as an Autobiographical Text. Studies in English Language Teaching, 5(4). 
Aydin, S. (2010). A Qualitative Research on Portfolio Keeping in English as a Foreign Language Writing. The Qualitative Report, 15(3), 475-488

Banfi, C. S. (2003). Portfolios: Integrating Advanced Language, Academic, and Professional Skills. ELT Journal, 57(1), 34-42. https://doi.org/10.1093/elt/57.1.34

Burksaitiene, N., \& Tereseviciene, M. (2008). Integrating alternative learning and assessment in a course of English for law students. Assessment \& Evaluation in Higher Education, 33(2), 155-166. https://doi.org/10.1080/02602930601125699

Caner, M. (2010) Students Views on Using Portfolio Assessment in EFL Writing courses. Anadolu University Journal of Social Sciences, 10(2), 223-236.

Chung, S. (2012) Portfolio Assessment in ESL Academic Writing Examining the Effects of Reflection in the Writing Process. Unpublished thesis. Graduate College of the University of Illinois at Urbana-Champaign.

Cohen, L., Manion, L., \& Morrison, K. (2007) Research Methods in Education. London: Routledge

Cooper, T. (1999). Portfolio assessment: A guide for lecturers, teachers and course designers. Quinns Rocks: Praxis Education.

Fithri, E. (2015). The Application of Portfolios to Asses Progress in Writing EFL students at Secondary School in Banda Aceh. Studies in English Language and Education, 2(1).

Ghoorchaei, B., Tavakoli, M., \& Ansari, D. (2010). The Impact Of Portfolio Assessment On Iranian EFL Students' EssayWriting: A Process-Oriented Approach. GEMA Online тм Journal of Language Studies, 10(3).

Hagstorm, F. (2006). Formative learning and assessment. Communication Disorders Quarterly, 28(1), 24-36. https://doi.org/10.1177/15257401060280010301

Hedge, T. (2000). Teaching and learning in the language classroom. Oxford: Oxford University Press.

Hung, S. (2009). Promoting Self- assessment Strategies: An Electronic Portfolio Approach. The Asian ELT Journal Quarterly, 11(2), 129-146.

Huang, J. (2012). The Implementation of Portfolio Assessment in Integrated English Course. English Language and Literature Studies, 2(4), 15-21.

Johns, A. M. (1991). Interpreting an English competency examination. Written Communication, 8, 379-401. https://doi.org/10.1177/0741088391008003004

Klenowski, V. (2002). Developing portfolios for learning and assessment: Process and product. London: Routledge Falmer.

Mabry, L. (1999). Portfolio plus: A critical guide to alternative assessment. Thousand Oaks: Corwin Press. 
Nezakatgoo, B. (2011). The Effects of Portfolio Assessment on Writing of EFL Students. English Language Teaching, 4(2), 231-241. https://doi.org/10.5539/elt.v4n2p231

Ozturk, H., \& Cecen, S. (2007). The effects of portfolio keeping on writing anxiety of EFL students. Journal of Language \& Linguistic Studies, 3(2), 218-236.

Paesani, K. (2006). Exercices de style": Developing multiple competencies through a writing portfolio. Foreign Language Annals, 39(4), 618-639. https://doi.org/10.1111/j.1944-9720.2006.tb02280.x

Paris, S. \& Ayres, L. (1994). Becoming reflective students and teachers: with portfolios and authentic assessment. Washington, DC: American Psychological Association. https://doi.org/10.1037/10158-000

Pollari, P. (2000). This is my portfolio": Portfolios in upper secondary school English studies. (ERIC Document Reproduction Service No. ED450415)

Phye, G. D. (Ed.) (1997). Handbook of classroom assessment: learning, achievement, and adjustment. San Diego, CA: Academic Press.

Song, B., \& August, B. (2002). Using portfolios to assess the writing of ESL students: A powerful alternative? Journal of Second Language Writing, 11(1), 49-72. https://doi.org/10.1016/S1060-3743(02)00053-X

Tannenbaum, J. (1997). Practical ideas on alternative assessment for ESL students. ERIC Digest.

Weigle, S. (2002) Assessing Writing. Cambridge: Cambridge University Press. https://doi.org/10.1017/CBO9780511732997

Winch, G., Ross Johnston, R., Holliday, M., Ljungdahl, L., \& March, P. (2001). Literacy: Reading, writing and children's literature. Melbourne: Oxford University Press.

Yurdabakan, I., \& Erdogan, T. (2009). The effects of portfolio assessment on reading, listening and writing skills of secondary school prep class students. The Journal of International Social Research, 2(9), 526-538.

Zhang, S. (2009) Has Portfolio Assessment Become Common Practice in EFL Classrooms? Empirical Studies from China. English Language Teaching, 2(2), 89-118. https://doi.org/10.5539/elt.v2n2p98 